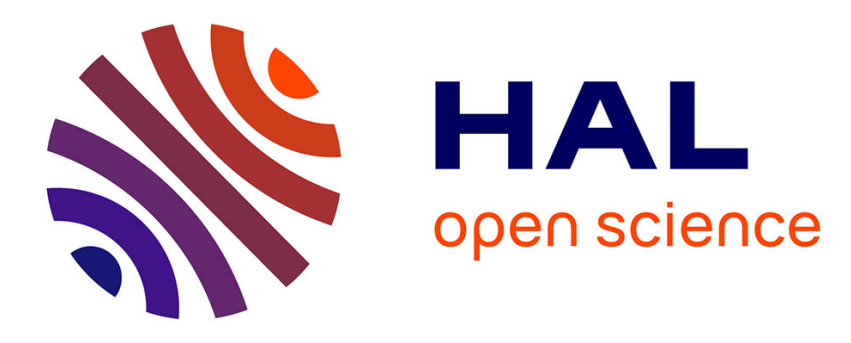

\title{
Rare Earth Doping Effect on the Electrical Properties of $\mathrm{Cu}-Z n F e r r i t e s$
}

\author{
A. Sattar, K. El-Shokrofy
}

\section{To cite this version:}

A. Sattar, K. El-Shokrofy. Rare Earth Doping Effect on the Electrical Properties of Cu-ZnFerrites. Journal de Physique IV Proceedings, 1997, 07 (C1), pp.C1-245-C1-246. 10.1051/jp4:1997194 jpa00255141

\section{HAL Id: jpa-00255141 \\ https://hal.science/jpa-00255141}

Submitted on 1 Jan 1997

HAL is a multi-disciplinary open access archive for the deposit and dissemination of scientific research documents, whether they are published or not. The documents may come from teaching and research institutions in France or abroad, or from public or private research centers.
L'archive ouverte pluridisciplinaire HAL, est destinée au dépôt et à la diffusion de documents scientifiques de niveau recherche, publiés ou non, émanant des établissements d'enseignement et de recherche français ou étrangers, des laboratoires publics ou privés. 


\title{
Rare Earth Doping Effect on the Electrical Properties of $\mathrm{Cu}-\mathrm{Zn}$ Ferrites
}

\author{
A.A. Sattar and K.M. El-Shokrofy* \\ Physics Department, Faculty of Science, Ain Shams University, Cairo, Egypt \\ * Physics and Mathematical Engineering Department, Faculty of Engineering, Menoufia University, \\ Shebin El-Kom, Egypt
}

\begin{abstract}
Samples of the chemical formula $\mathrm{Cu}_{0.5} \mathrm{Zn}_{0.5} \mathrm{Fe}_{2-\mathrm{x}} \mathrm{R}_{\mathrm{x}} \mathrm{O}_{4}$ where $\mathrm{R}$ is a rare earth ion (R=La,Nd,Sm, Gd and $\left.\mathrm{Dy}\right)$ and $x=0$ and $x=0.1$ have been investigated The $X$-ray diffraction analysis showed a single spinel phase. The lattice constant was found to be nearly independent of the type of $\mathrm{R}$ ions. The temperature dependence of the electrical resistivity indicated a change in the activation energy on passing the Neel temperature. The thermo electric power was found to be nearly independent of temperature but depends on the type of $R$ ions. Our results are well explained using the hopping conduction mechanism in these ferrites.
\end{abstract}

\section{Introduction}

The effect of substituting trivalent ions from iron [1,2] including La ions [3] in ferrites have been investigated. Patil et al. [3] studied the system $\mathrm{CuLa}_{2 \mathrm{x}} \mathrm{Fe}_{2-2 \mathrm{x}} \mathrm{O}_{4}$ and two phases of spinel and pervoskite were detected for $\mathrm{x} \geq 0.4$ in addition to impurity lines of $\gamma \mathrm{Fe}_{2} \mathrm{O}_{3}$ and $\mathrm{CuFeO}_{2}$. On the other hand,Kolekar et.al. [4] studied the $\mathrm{Cu}-\mathrm{Cd}$ mixed ferrites with $\mathrm{Gd}{ }^{3+}$ substituted for $\mathrm{Fe}^{3+}$ ions. The X-ray analysis indicated the presence of $\mathrm{GdFeO}_{3}$ pervoskite phase in the resulting compound. The presence of multi-phase in the sample will affect its actual internal physical properties. Therefore we aimed in this work to study the electrical properties of single phase of $\mathrm{Cu}-\mathrm{Zn}$ ferrites doped with different types of rare earth ions.

\section{Experimental}

Samples of the chemical formula $\mathrm{Cu}_{0.5} \mathrm{Zn}_{0.5} \mathrm{Fe}_{2-\mathrm{x}} \mathrm{R}_{\mathrm{x}} \mathrm{O}_{4}(\mathrm{R}=\mathrm{La}, \mathrm{Nd}, \mathrm{Sm}, \mathrm{Gd}$, and Dy), where $\mathrm{x}=0$ and 0.1 , were prepared by the usual ceramic technique. High purity oxides, $99.9 \%$, of $\mathrm{CuO}, \mathrm{ZnO}, \mathrm{Fe}_{2} \mathrm{O}_{3}$ and $\mathrm{R}_{2} \mathrm{O}_{3}$ were used. . The oxides were presintered at $900^{\circ} \mathrm{C}$ for $30 \mathrm{hrs}$, finally sintered at $1000^{\circ} \mathrm{C}$ for $6 \mathrm{hrs}$ in two cycles and then slowly cooled at a rate of $1^{\circ} \mathrm{C} / \mathrm{min}$. X-ray diffraction patterns were performed using a diffractometer type PW3710 with cu $\mathrm{k}_{\alpha}$ radiation. For electrical resistivity measurements, the sample surfaces were nubbed with In-Ga as proved to be a good contact for ferrites. A temperature difference of $5^{\circ} \mathrm{C}$ was kept constant during thermo electric power measurements. A Keithley type 175 autoranging multimeter was used for measuring both the electrical resistivity and thermo electric power.

\section{Results and discussion}

The X-ray diffraction patterns showed that all samples are formed in cubic single spinel phase. No foreign impurity lines could be detected. The lattice parameter a ( $\AA$ ) was calculated using Braggs law and these values are given in table (1). We notice that the lattice parameter for all samples seems to be independent of the type of doped rare earth ions. This means that the rare earth ions occupy either the iron positions or go to the grain boundaries. However we have to exclude the probability that the rare earth ions occupy the A-sites of $\mathrm{Fe}^{3+}$ ions. This is due to the fact that the tetrahedral sites are small to be occupied by the large rare earth ions which have large ionic radius. Of course the probability of occupancy of the octahedral $(B)$ sites by the rare earth ions will increase with decreasing the $R$ ionic radius.

Table 1: Variations of the lattice constant and Neel temperature for aifferent doping types

\begin{tabular}{|c|c|c|c|c|c|c|}
\hline $\mathrm{R}$ ion & $-\cdots$ & $\mathrm{La}$ & $\mathrm{Nd}$ & $\mathrm{Sm}$ & $\mathrm{Gd}$ & $\mathrm{Dy}$ \\
\hline $\mathrm{a}(\AA)$ & 8.40 & 8.41 & 8.42 & 8.42 & 8.42 & 8.41 \\
\hline $\mathrm{T}_{\mathrm{N}}(\mathrm{K})$ & 420 & 429 & 425 & 416 & 425 & 408 \\
\hline
\end{tabular}

Fig. (1-a) shows the variations of the electrical resistivity versus temperature for samples containing $\mathrm{La}, \mathrm{Sm}$ and $\mathrm{Gd}$. It 
is clear that the resistivity decreases linearly with increasing temperature. There are changes in the activation energy $E_{\rho}$ at 429,416 and 425K for La,Sm and Gd doped samples respectively. Similar behavior, but not represented, was obtained for $R=0, N d$ and $D y$ with a change in $E_{\rho}$ at 420,425 and $408 K$ respectively.

Fig. (1-b) shows the changes of thermo electric power $(\alpha)$ with temperature for samples doped with La.Sm and Gd. For these samples the sign of $(\alpha)$ is negative which indicates that the dominant charge carriers are electrons. In the measured temperature range. $(\alpha)$ is nearly independent of temperature. Similar behavior was found for samples with $R=0, N d$ and $D y$ except that the undoped sample, $(\alpha)$ is changed to positive values at high temperatures.

The Neel temperature of $\mathrm{CuFe}_{2} \mathrm{O}_{4}$ was reported to be $\cong 753 \mathrm{~K}[5]$ and substitution of $\mathrm{Zn}$ or $\mathrm{Cd}$ for $\mathrm{Cu}$ in $\mathrm{CuFe} \mathrm{O}_{4}$ reduces this temperature. For our undoped sample we found a change in $E \rho$ at $420 \mathrm{~K}$. Therefore such a change in $E \rho$ can be attributed to changes from ferri - to paramagnetic state. As the lattice parameter does not change on doping. it allows us to assume that the structure remains the same. Accordingly, the changes of $E_{\rho}$ for all studied samples can be attributed to order-disorder transition. The values of $T_{N}$ are given in table (1). As the R-R and R-Fe interactions are small compared with $\mathrm{Fe}-\mathrm{Fe}$ interactions on the B-sites, then the Fe-Fe interactions will be the dominant one. This gives an explanation for the nearly constant value of $\mathrm{T}_{\mathrm{N}}$ around $422 \pm 6^{\circ} \mathrm{K}$. Similar behavior was found in rare earth doped $\mathrm{Ni}-\mathrm{Zn}$ ferrites[6].

The constancy of $(\alpha)$ and decreasing the electrical resistivity in the same temperature range supports the hopping conduction mechanism as discussed in our previous paper [?].

Fig. $(2-a . b)$ shows the variations of both $\rho$ and $(\alpha)$, at $T=435 \mathrm{~K}$. with different types of $R$ in the order of a decrease the ionic radius. It is clear that the absolute value of $(\alpha)$ increases with decreasing the ionic radius up to $\mathrm{Sm}$ ion then decreases again. According to the relation $\quad \alpha=2.3(\mathrm{~K} / \mathrm{e}) \log \left(\mathrm{N}_{\mathrm{o}} / \mathrm{n}\right)$ where $\mathrm{N}_{\mathrm{o}}$ is the density of states and $\mathrm{n}$ is the carrier concenteration. the increase of $(\alpha)$ means that $n$ is decreasing with decreasing the $R$ ionic radius. This leads to increase of $\rho$ which we found experimentally. This leads us to suppose that the occupation of B-sites by the R ions depends not only on the ionic radius but also on a site preference of these ions. The presence of the rare earth ion on the B-site impedes the motion of charge carriers. Hence Sm,Gd and Dy have high site preference to occupy B-sites. It may be of value to mark that a zigzag curve was obtained for $\rho$ in case of multi-phase system [6]. This reflects the importance of obtaining a single spinel phase.

\section{Conclusion}

In our samples. both the lattice parameter and the Neel temperature are found to be independent of the type of rare earth ions (R). The doping of $\mathrm{Cu}-\mathrm{Zn}$ ferrites with $\mathrm{R}$ affects both the resistivity and thermo electric power specially with small radius of $R$. The conduction mechanism is well explained using the hopping model

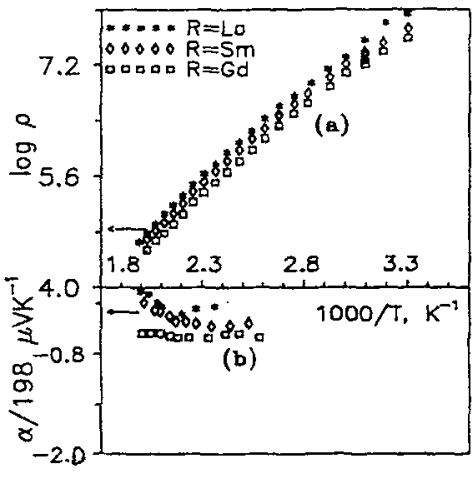

Fig. (1) Variation of (a) resistivity and (b) thermoelectric power versus. temperature

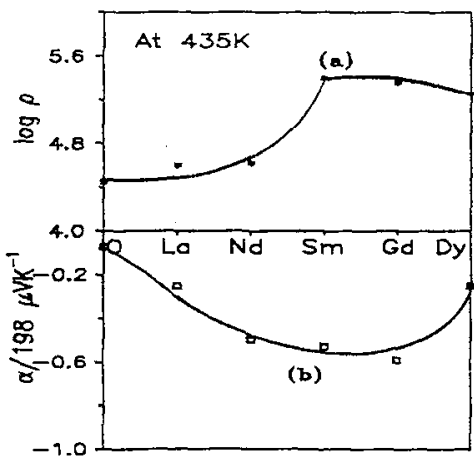

Fig. (2) Variation of (a) resistivity and

(b) thermoelectric power versus. the doped rare earth ion.

\section{References}

[1] Belove K P, Antoshina L A and Moreosyan A S . Sov. Phys. Solid State 25 (1993) 1609

[2] Ahmed M A. Tawfik A.El-Nimr M K and El-Hasab, J. Mater .Sci. 10 (1991) 549

[3] Patil S A. Otari S M, Mahajan V C. Patil M G, Patil A B, Soudagar M K. Patil B L and Sawant.Solid State Commun. 78 (1991) 39

[4] Kolekar C B. Kamble P N and Vaingankar. J. Magn. Magn.Mater.138 (1994) 21 ]

[5] Tang Xi. Manthiram and Goodenough J B. J. Solid State Chem. 79 (1989) 250

[6] Rezlescu N, Rezlescu E. Pasnicu C and Craus M L. J. Phys. Condens.Matter 6 (1994) 5707

[7] Sattar A A. J.Mater.Sci.Lett. 15 (1996) 1090 